\title{
RELATO DECASO Simulação de transtorno de estresse pós-traumático secundário a combate em exame pericial
}

\author{
Feigned combat-related post-traumatic stress disorder \\ in a forensic psychiatric examination \\ Mauro V. Mendlowicz ${ }^{1,2}$, William Berger²
}

\begin{abstract}
RESUMO
Neste artigo, apresentamos relato de uma perícia de um caso de simulação de transtorno de estresse pós-traumático. Nosso objetivo era apresentar o leitor às dificuldades que o perito pode encontrar diante desses casos e demonstrar como um exame atento, combinado com conhecimento das peculiaridades dessa doença, pode contribuir poderosamente para o diagnóstico correto.
\end{abstract}

\begin{abstract}
In this article, we present the report of the forensic examination of a case of malingered post-traumatic stress disorder. Our goal was to introduce the reader to the hurdles forensic psychiatric have to face while dealing with similar cases and to demonstrate that a careful examination combined with a good knowledge about this disorder is critical to reach the correct diagnosis.
\end{abstract}

\section{INTRODUÇÃO}

O transtorno de estresse pós-traumático (TEPT) é um transtorno relativamente comum - com uma prevalência para a vida toda estimada em 7,5\% (Kessler, 1995') - e de grande impacto clínico. Mas sua importância nos contextos forenses é desproporcional, maior que sua inegável estatura epidemiológica e clínica. Diagnósticos de TEPT - reais ou supostos - são uma causa comum para a realização de perícias visando à obtenção de indenizações por vias legais.

O relato de uma perícia de um caso de simulação de TEPT que se segue busca exemplificar as dificuldades que o perito (e, às vezes, o clínico também) encontra perante esses casos e demonstrar como um exame atento combinado com conhecimento das peculiaridades dessa doença pode contribuir poderosamente para chegar ao diagnóstico correto.

\section{DESCRIÇÃO DO EXAME PERICIAL}

\section{Identificação}

Sr. A., brasileiro, 54 anos, sexo masculino, cor parda, casado, biscateiro, quarta série do ensino fundamental, natural de Maceió, Alagoas.

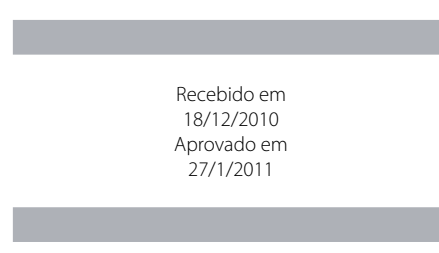

1 Universidade Federal Fluminense (UFF), Departamento de Psiquiatria e Saúde Mental. 2 Universidade Federal do Rio de Janeiro (UFRJ), Instituto de Psiquiatria.

Endereço para correspondência: Mauro V. Mendlowicz Departamento de Psiquiatria e Saúde Mental da Universidade Federal Fluminense (UFF) Rua Marques de Paraná, 303, Fundos, terceiro andar do Prédio Anexo - 24033-900 - Niterói, Rio de Janeiro, Brasil Telefone: (+ 55 21) 2629-9351

E-mail:msm@vm.uff.br 


\section{Elementos colhidos nos autos}

"Que o pedido de reforma do Autor gira em torno da ALIENAÇÃO MENTAL..., pois é o Autor pessoa inválida e incapaz de exercer qualquer atividade laborativa."

"...O serviço militar que prestou na República Dominicana agiu como fator desencadeante deste mal que, atualmente, aflige o Autor..."

\section{Queixa principal}

"Tenho uma metralhadora na cabeça."

\section{História da doença atual}

Todos os dados anamnésicos foram colhidos, por causa da falta de colaboração do periciado, com sua esposa, a Sra. B. Os dois se conheceram em 1966 e se casaram em 1971. Segundo Ihe relatou a genitora do examinando, este era "nervoso" desde antes da "guerra" (na verdade, a participação no Destacamento Brasileiro da Força Armada Interamericana - FAIBRÁS - na República Dominicana em 1956-1966). Ao retornar ao Brasil no final de sua experiência militar, estava ainda "mais nervoso". O examinando não fez qualquer tratamento enquanto estava a serviço do exército e recebeu baixa logo após seu retorno ao Brasil.

Ao longo dos anos, o periciado trabalhou muitas vezes como biscateiro, mas "ficava nervoso e largava (logo) o emprego". O "nervosismo" agravou-se progressivamente a partir de 1987, logo atingindo a configuração e a intensidade atuais. O periciado foi ao psiquiatra duas vezes (uma em 1988 e a outra em 1992), mas rasgou as receitas de Rohypnol $^{\circledR}$ e Rivotril ${ }^{\circledR}$ que Ihe foram entregues na segunda ocasião. Desde então, a despeito do seu estado, o examinando não se consultou com qualquer especialista em saúde mental nem tampouco empreendeu qualquer tratamento, fato que a Sra. B. justificou pela dificuldade de acesso aos serviços de saúde. A Sra. B. afirmou categoricamente que o quadro apresentado pelo periciado durante a entrevista (vide exame psíquico abaixo) corresponde a seu estado habitual.

Segundo a Sra. B., o periciado não desenvolve qualquer atividade produtiva. Não se mostra agressivo, seja verbal ou fisicamente. Alimenta-se irregularmente, sendo necessária, às vezes, a ajuda de sua mulher para que faça suas refeições. Da mesma forma, a Sra. B. alega ser amiúde necessário estimulá-lo para que faça sua higiene. O casal não tem vida sexual desde 1987.

\section{Antecedentes pessoais e familiares}

O periciado e sua esposa se conheceram em 1966, casaram-se em 1971 e tiveram três filhos. Durante alguns anos, contaram com a ajuda do pai da Sra. B. para sobreviver, mas este faleceu em 1981. Desde então, a família tem passado necessidades.

\section{Antecedentes patológicos}

A esposa do periciado nega que ele padeça de etilismo, de tabagismo, de doenças físicas ou que faça uso de drogas.

\section{Exame psíquico}

O periciado chegou ao local acompanhado de sua esposa. É um homem de estatura mediana e idade aparente compatível com a cronológica. Seu rosto é um pouco infiltrado. Mostrava-se cabisbaixo, com cenho continuamente franzido e mancava discretamente. Trajava vestes próprias, muito modestas, mas em bom estado higiênico. Apresentava um cavanhaque e barba por fazer. Não cumprimentou o examinador.

O casal sentou-se no local indicado. Quase incontinenti, o periciado afundou o rosto em suas mãos e se pôs a murmurar como que para si mesmo: "Quero ir para o quartel...".

Sua esposa explicou então que o periciado só saía de casa para ir ocasionalmente a um determinado quartel, mas não soube explicar como é que um militar reformado de baixa patente tinha livre acesso a instalações militares.

Entrementes, o examinando começou a falar sozinho em tom mais elevado:

"...EU AVISEI QUE ESTAVA MINADO, EU AVISEI, MAS NINGUÉM ME OUVIU!!!!!!... Tem uma metralhadora tocando na minha cabeça... Eu quero ficar junto com eles...".

Seguiu-se um período de silêncio no qual o examinando permaneceu cabisbaixo, mexendo apenas com os pés. Em seguida, ele rompeu espontaneamente o silêncio, dizendo em tom de súplica para sua mulher: "...vamos embora...".

Convidado diversas vezes a falar sobre sua vida e seus problemas, o periciado permaneceu sempre em silêncio. Ocasionalmente, punha as mãos na cabeça, baixava-a e bufava. Volta e meia repetia "vamos embora" com um tom desalentado. Em uma ocasião, beijou uma medalhinha que trazia no pescoço sem dar qualquer explicação.

A despeito de sua aparente insistência em ir embora, o examinando em nenhum momento tomou a iniciativa de se levantar. Apenas quando o entrevistador deu a entrevista por concluída, o periciado se levantou e se dirigiu para a porta sem se despedir.

\section{Súmula psicopatológica}

Aparência relativamente cuidada. Atitude predominantemente negativista que, intercalada com episódios de conduta teatral, comprometeu a extensão e a profundidade da investigação psicopatológica. Consciência e orientação não aferidas. Manifestações emocionais objetivas restritas ao polo ansioso/depressivo. Presença de solilóquios. Características formais do pensamento não avaliadas. Não constatei a presença de atividade delirante ou de distúrbios da sensopercepção. Inteligência e funções mnêmicas não aferidas. Atividade psicomotora reduzida. Presença aparente de consciência de morbidade. Capacidade de planejamento e pragmatismo não avaliados. 


\section{Exame físico}

Nada a registrar de importância médico-legal, do ponto de vista psiquiátrico.

\section{Exames complementares}

Não são necessários para o caso em tela.

\section{Diagnóstico}

De acordo com os dados colhidos durante a entrevista, não é possível concluir que o examinando seja portador no momento de algum transtorno mental.

\section{DISCUSSÃO}

A simulação é a produção ou invenção intencional de sintomas ou incapacidades físicas ou psicológicas motivada pela busca de vantagens pessoais (e.g., indenizações) ou pela tentativa de evadir-se a responsabilidades (e.g., obter dispensa do serviço militar).

Durante o exame pericial, o periciado procurou simular um quadro de transtorno de estresse pós-traumático (TEPT). Esse transtorno é descrito na $10^{\text {a }}$ revisão da Classificação Internacional das Doenças (CID-10) como:

"... uma resposta tardia e/ou protraída a um evento ou situação estressante de uma natureza excepcionalmente ameaçadora ou catastrófica, a qual provavelmente causa angústia invasiva em quase toda as pessoas (p. ex., desastre natural ou feito pelo homem, combate, ..., testemunhar a morte violenta de outros,,$\ldots.)^{\prime \prime}$

Os sintomas de TEPT podem ser agrupados em três categorias:

1) Experiências involuntárias de revivescência do episódio traumático, que se apresentam sob a forma de recordações e sonhos recorrentes e aflitivos ou como flashbacks.

2) Esquiva persistente dos estímulos associados com o trauma, manifesta como esforços para evitar pensamentos, atividades, locais ou pessoas que ativem recordações do trauma.

3) Sintomas persistentes de excitabilidade aumentada, como dificuldade em conciliar e manter o sono, irritabilidade, dificuldade em concentrar-se, hipervigilância e resposta de sobressalto exagerada.

Nas diretrizes diagnósticas para TEPT providas pela CID-10, consta que "este transtorno não deve ser diagnosticado a menos que haja evidência de que ele surgiu dentro de seis meses após um evento traumático de excepcional gravidade".

Na versão atual da classificação da Associação Americana de Psiquiatria, a DSM-IV-TR, o TEPT é classificado entre os transtornos de ansiedade. Na CID-10, o TEPT é classificado sob a rubrica "Transtornos neuróticos, relacionados ao estresse e somatoformes".

No decorrer da entrevista e do exame, observamos diversas inconsistências e contradições que deixaram claro que o quadro clínico apresentado pelo periciado não correspondia ao diagnóstico de TEPT.

\section{Evento traumático}

A ocorrência de exposição a um evento traumático, elemento-chave do diagnóstico de TEPT, não ficou comprovada. O simples fato de que o periciado integrou uma força de paz não garante que ele tenha sido exposto a eventos traumáticos. A atuação do Destacamento Brasileiro da Força Armada Interamericana (FAIBRÁS) na República Dominicana em 1956-1966 foi pacífica, não estando registrado o envolvimento em situações de combate.

\section{Elemento cronológico}

Geralmente, os sintomas de TEPT se manifestam nos três primeiros meses após o trauma. A CID-10, como visto acima, exige que os sintomas apareçam no máximo seis meses após o evento traumático. Um estudo recente revelou que o TEPT de início tardio verdadeiro é um fenômeno raro, sendo muito mais comum a reativação ou a exacerbação de sintomas preexistentes (Andrews et al.2, 2007). A erupção aparentemente imotivada de um pretenso quadro de TEPT duas décadas depois dos eventos supostamente traumáticos é, portanto, a exceção à regra. Por outro lado, deve-se considerar que os sintomas vieram a se manifestar num contexto que envolve importantes ganhos secundários (ação judicial visando responsabilizar a União pela suposta incapacidade do periciado).

\section{Quadro clínico}

O TEPT é considerado um transtorno de ansiedade (segundo a DSM-IV) ou um transtorno relacionado aos quadros neuróticos (segundo a CID-10). O quadro clínico apresentado pelo examinando durante a entrevista não é compatível com um transtorno neurótico ou de ansiedade. O quadro que descrevemos combina dois componentes: a) uma atitude negativista que é observada apenas em quadros psicóticos, dissociativos ou de simulação; e b) uma representação teatralizada do que seria a revivescência de um evento traumático. Essa combinação é tosca, mas potencialmente efetiva, uma vez que ao mesmo tempo em que dificulta que o periciado seja examinado com profundidade, serve para veicular a mensagem que é de seu interesse. Em que pese a ocorrência mais ou menos frequente de sintomas dissociativos e psicóticos no TEPT (Braakman et al. ${ }^{3}, 2009$ ), o quadro apresentado pelo periciado é mais evocativo das representações cinematográficas desse transtorno do que de sua realidade clínica. 


\section{Sintomas de esquiva}

Também deve ser registrado o fato de que a Sra. B. afirmou e insistiu que o examinando tem por hábito visitar um determinado quartel do exército perto de sua residência. Ora, por definição, o padecente de TEPT necessariamente evita pensamentos, pessoas, situações e locais que o façam se lembrar do evento traumático. Nesse contexto, seria inexplicável a insistência paradoxal do periciado em frequentar instalações militares. E sem sintomas de esquiva não é possível selar o diagnóstico de TEPT.

\section{DISCUSSÃO}

O caso apresentado ilustra as dificuldades encontradas para fazer um diagnóstico de TEPT em situações periciais. O exame pericial normalmente é feito sob condições adversas. $O$ periciado em geral tem grande interesse em ver selado o diagnóstico de TEPT, uma vez que esse diagnóstico representa amiúde um atalho para obter indenizações do poder público. Frequentemente, há escassez (ou mesmo sonegação ativa) de informações necessárias para fechar ou excluir tal diagnóstico e a decisão tem de ser baseada em elementos pontuais. É vital, portanto, procurar obter o máximo possível de informações sobre o caso em todas as fontes disponíveis (internet, autos judiciais, prontuário médico, parentes, informantes e o próprio paciente). É preciso também conhecer profundamente as características do quadro de TEPT para estar apto a detectar possíveis inconsistências do relato do periciado, principalmente levando-se em conta que hoje em dia as informações básicas sobre essa doença são facilmente acessíveis pela internet e pela mídia escrita e eletrônica.

Nesse contexto, as informações fragmentárias obtidas pelo perito têm que ser avaliadas e ponderadas para que se chegue ao diagnóstico correto. No caso em tela, a ausência de evento traumático identificável, a suposta erupção ultratardia do quadro e a apresentação clínica duvidosa seriam o bastante para excluir o diagnóstico de TEPT. Mas na ânsia de fortalecer o seu caso, o periciando e sua parceira incidiram em um erro comum nas simulações de TEPT de origem militar: tentaram fazer ressaltar a vinculação do periciado à vida militar. A partir desse momento, tornou-se possível fazer um diagnóstico positivo da simulação, uma vez que não é possível diagnosticar o TEPT na ausência da esquiva aos fatos e situações que evoquem o suposto evento traumático.

\section{CONCLUSÃO}

Embora essas observações pareçam ser aplicáveis exclusivamente aos exames periciais, não se deve descartar sua relevância para as situações clínicas. Muitas vezes, o primeiro passo para dar início a ações de indenização consiste em obter uma declaração do clínico com determinados diagnósticos. É preciso, portanto, que todos os especialistas em saúde mental estejam familiarizados com as peculiaridades do TEPT e preparados para identificar as tentativas de simulá-lo.

\section{REFERÊNCIAS}

1. Kessler RC, Sonnega A, Bromet E, Hughes M, Nelson CB. Posttraumatic stress disorder in the National Comorbidity Survey. Arch Gen Psychiatry. 1995;52(12):1048-60.

2. Andrews B, Brewin CR, Philpott R, Stewart L. Delayed-onset posttraumatic stress disorder: a systematic review of the evidence. Am J Psychiatry. 2007;164(9):1319-26.

3. Braakman MH, Kortmann FA, Van den Brink W. Validity of "post-traumatic stress disorder with secondary psychotic features": a review of the evidence. Acta Psychiatr Scand. 2009;119(1):15-24. 